\title{
Anatomic and physiological bases of social blushing: speculations from neurology and psychology
}

\author{
W.D. Cutlip II $^{1}$ and M.R. Leary ${ }^{2}$ \\ 'Departments of Neurology, and Department of Behavioral Medicine and Psychiatry, \\ West Virginia University School of Medicine, Morgantown, WV, and ${ }^{2}$ Department of \\ Psychology, Wake Forest University, Winston-Salem, NC 27109, USA
}

Correspondence to: M.R. Leary at above address

\begin{abstract}
Although a common and occasionally troubling reaction, social blushing has received little systematic attention from either medical or behavioral researchers. This article reviews what is known of the physiological and psychological processes that mediate social blushing, and speculates regarding the role of central mechanisms in the phenomenon. Blushing is characterized by the unusual combination of cutaneous vasodilatation of the face, neck, and ears, accompanied by activation of the sympathetic nervous system. Psychologically, blushing appears to occur when people receive undesired social attention from others and may be analogous to the appeasement displays observed in non-human primates. Although poorly understood, the central mechanisms that mediate blushing obviously involve both involuntary autonomic effector systems and higher areas that involve self-reflective thought. Questions for future research are suggested.
\end{abstract}

Keywords: Blushing - Embarrassment - Flushing - Limbic system

\section{INTRODUCTION}

Charles Darwin (1872/1955) referred to blushing as the most uniquely human of all emotional expressions. Although the faces of other animals redden with rage, only humans are known to blush. (Perhaps, as Mark Twain observed, only humans have good reasons to blush.) Despite the fact that social blushing is a commonplace and intriguing response, it has received only passing attention from researchers in neurology, psychiatry, psychology, and other fields. In this article, we review what is known about blushing and speculate regarding its neurological and psychological underpinnings.

The human face flushes in a variety of circumstances and as a result of many agents. Many conditions associated with bilateral flushing have been cited, including menopause, ethanol ingestion, anaphylactic reactions, mastocytosis, thyroid medullary carcinoma, carcinoid tumor, other neoplasms associated with vasoactive substance secretion, hypothalamic involvement by tumor, autonomic manifestations of seizures, severe hypertension, and, of primary interest in this article, embarrassing and socially awkward situations (Waldenstrom, 1977; Celesia et al., 1981; Freeman et al., 1992; Leary et al., 1992).

Researchers have attempted to delineate the mechanisms involved in various types of flushes both by contrasting the specific physiological reactions that accompany

(C) 1993 Rapid Communications of Oxford Ltd various flushes and by examining agents that pharmacologically induce and abolish different types of flushing (Phillips and Lightman, 1981; Collier and Fuller, 1983; Krause et al., 1991; Rybakowski and Weterle, 1991). Various humoral mediators of flushing have been indicated, including prostaglandins, substance $P$, and histamine (Freeman et al., 1992). Furthermore, flushing can be induced by warming the oral cavity (by ingesting hot liquids, for example) (Wilkin, 1988). The flush that sometimes accompanies intense anger or rage may result directly from mechanical manipulation of venous return (the Valsalva maneuver) (Wilkin, 1983).

The hot flushes that accompany menopause are likely caused by miscueing of hypothalamic regulatory centers (Wilkin, 1983). One study showed that the cardiovascular responses that accompany menopausal flushes are distinct from those that accompany social blushes. Whereas menopausal flushes were associated with increased blood flow in the hands but with no change in blood pressure, social blushing was accompanied by no change in hand blood flow, but by increased pulse rate and blood pressure (Ginsburg and O'Reilly, 1987).

Most research into the humoral, neural, and physiological processes involved in flushing have focused on nonsocial flushes associated with medical conditions such as 
those listed above, and the mechanisms involved in social blushing have received little attention. Thus, our description of the physiologic processes involved in social blushing is necessarily speculative, being based on extrapolations from other areas.

\section{THE BLUSH REGION}

In most people, blushing is confined to an area known as the "blush region"- the face, ears, neck, and upper chest (Waldenstrom, 1977; Wilkin, 1988; Shields et al., 1990). In noting the localization of blushing, Darwin (1872/1955) suggested that blushing is confined to the face because it is to that part of the body that other people most often direct their attention. Darwin's speculation is almost certainly wrong. Many other kinds of flushes, including the nonsocial flushes listed above, occur primarily, if not exclusively in this region.

Wilkin (1988) suggested three possible explanations for the localization of visible flushing to the blush region: (a) the cutaneous vasculature of this area may differ from that of other parts of the body in its responsivity to agents that cause flushing; (b) the neural mechanisms that control the vasculature of the blush region may differ from those that control other areas of cutaneous vasculature; or (c) the vasculature of the skin of the blush region may simply be more visible. Based on a study of the effects of the ingestion of hot water vs nicotinic acid on facial and forearm flushing, Wilkin obtained support for explanation (c). He concluded that the simplest explanation is that the facial cutaneous vasculature has a higher capacitance for erythrocytes than other parts of the body such as the forearm. The proportional increase in erythrocyte flux was roughly equivalent in the facial and forearm sites, yet flushing was more easily observed on the face. Furthermore, there are more capillary loops per square millimeter on the face than at other sites (Ryan, 1973b), and the subpapillary plexus is nearer the surface of the facial skin than other areas of the body (because the upper dermis is thinner) (Ryan, 1973a). Thus, facial flushes may be particularly visible because the face possesses a greater number of vessels, with greater capacitance, near the surface of the skin.

Although we concur that the vasculature of the face may differ from that of other parts of the body in ways that make flushing more apparent in the face than elsewhere, evidence based on non-social flushes may not apply to social blushing. Specifically, studies that have measured facial and peripheral blood flow (at sites on the forearm or hand) show that experimental manipulations designed to elicit embarrassment or social blushing cause facial temperature to increase at the same time that peripheral temperature either decreases or remains constant (Ginsburg and O'Reilly, 1987; Leary et al., 1990; Templeton and Leary, 1991; Leary et al., unpublished).
As a general rule, the sympathetic discharge of thoracolumbar postganglionic cells stimulates release of epinephrine (and a much smaller amount of norepinephine) from adrenal medulla that, in turn, elicits a generalized vasoconstrictive effect in skin. However, extirpated human facial vein demonstrates a vasodilatory response to norepinephine in a limited range of concentration, above which marked vasoconstriction is evoked (Mellander $e t$ al., 1982). Such vasodilatory responses can be mediated by direct action on alpha and beta receptors on smooth muscle in vessel walls or by modulation of autonomic tone. Thus, both neural and chemical influences can contribute to the final clinical manifestation of face reddening or blushing.

\section{PHYSIOLOGIC CONCOMITANTS}

Existing research on the physiological concomitants of blushing, though sparse, suggests that blushing is not characterized by a consistent physiologic response. Although embarrassment is often viewed as a special instance of social anxiety (Buss, 1980; Leary, 1983), patterns of physiologic activity during embarrassment do not always resemble those of an anxiety state. Unlike anxiety states, which are accompanied by indices of increased sympathetic arousal, disparate responses in cardiovascular systems (heart rate, systolic and diastolic blood pressure) have been found in various experimental conditions that have induced embarrassment or blushing. Furthermore, whereas anxiety states are accompanied by decreased blood flow to the face (which is manifested by facial blanching), embarrassed blushing is associated with increased facial blood flow (Leary et al., 1992).

Blushing tends to be accompanied by increased heart rate and blood pressure (Ginsburg and O'Reilly, 1987), but whether this increase mimics that accompanying anxiety depends on the degree to which the embarrassing event was expected. When subjects were forewarned of an impending embarrassing experience, their cardiovascular reactivity during the event was significantly lower than when embarrassment occurred unexpectedly. Responses to unexpected embarrassment closely resembled a state of anticipatory social anxiety (in which subjects only contemplated an upcoming embarrassing event), with significant elevations in heart rate and blood pressure. However, embarrassment that was anticipated led to only slight increases in heart rate and blood pressure that were significantly lower than those observed in anxiety states (Leary et al., 1990; Leary et al., unpublished). Interestingly, fingertip temperature, which is inversely correlated with sympathetic-mediated vasoconstriction, decreased equally in both anxiety states and during embarrassment (Leary et al., unpublished).

Thus, although embarrassment sometimes resembles an 
anxiety state (and people report feeling tense or anxious when blushing; Leary and Meadows, 1991), the available evidence suggests that the physiologic concomitants of states that accompany blushing reflect more than pure sympathetic discharge.

One possibility is that, whereas anticipatory social anxiety reflects an active fear response to situations in which confrontative, remediative, or evasive action is contemplated, embarrassment reflects a passive fear response characterized by resignation or behavioral inhibition (Hamilton, 1989). If research based on animal models may be extrapolated to humans, it is possible that anxiety states are sympathetically mediated whereas blush states involve both sympathetic and parasympathetic activity (Smith et al., 1974; Smith and Tobey, 1983). Such a mixed autonomic response in which sympathetic activation is accompanied by heart rate deceleration is characteristic of certain other emotional states, such as disgust (Eckman $e t$ al., 1983; Hubert and de Jong-Meyer, 1990).

\section{PSYCHOLOGICAL THEORIES OF BLUSHING}

In the more than a century since Darwin's (1872/1955) seminal essay on blushing, few studies have been conducted on the psychological antecedents of the reaction (for a review, see Leary et al., 1992). Even so, the dearth of empirical data on social blushing has not deterred a wealth of speculation regarding its psychological causes. Existing explanations of blushing can be classified, roughly, into four general categories.

\section{Psychodynamic approaches}

Psychodynamic theorists have offered an array of explanations of blushing (see Karch, 1971, for a review), but the most common theme is that blushing is a response to repressed genital excitation, particularly in the form of exhibitionism. According to this view, people who have an unfulfilled wish to expose their genitals to other people convert this urge into a physical reaction, shunting blood from the genitals to the face (Benedek, 1925; Fenichel, 1945; Feldman, 1962).

\section{Interpersonal appraisal}

In his discussions of blushing, Darwin (1872/1955) suggested that people blush as a result of concerns with others' evaluations. As he noted, it is "the thinking of what others think of us which excites a blush" (p. 325). This theme appeared most recently in the work of Harris (1990) who proposed that the psychological state that accompanies blushing involves an awareness that one has conveyed an image to others that is discrepant from the image one desired to convey.

\section{Remedial approaches}

Somewhat surprisingly for the father of evolutionary theory, Darwin (1872/1955) argued that blushing served no useful purpose: "it makes the blusher to suffer and the beholder uncomfortable, without being of the least service to either of them" (p. 336). Many other writers have disagreed. Even before Darwin, Burgess (1839) suggested that blushing serves to indicate to others that the person knows he or she has violated certain social or moral rules. MacCurdy (1930), Karch (1971), and Castelfranchi and Poggi (1990) offered similar explanations that focused on the remedial nature of blushing.

Growing evidence supports the idea that people who have conveyed undesired impressions of themselves to others wish to express their embarrassment to those who have witnessed their incompetent, immoral, or inappropriate behavior (Miller and Leary, 1992). The non-verbal behaviors that accompany embarrassment-such as downcast eyes, silly smiling, and blushing - may serve an important interpersonal function. By publicly conveying their embarrassment, people acknowledge that a facethreatening event has occurred, express their support for the norms or rules they have violated, and implicitly note that their inappropriate, foolish, or undesired behavior should not be taken to reflect on their personality, character, or ability. Failing to appear embarrassed, in contrast, conveys that the person is either unaware of or unconcerned about his or her deviant behavior. Indeed, verbal and non-verbal expressions of embarrassment serve a remedial function, improving observers' reactions to a person who has behaved in an embarrassing fashion (Semin and Manstead, 1982; Castelfranchi and Poggi, 1990).

\section{Undesired social attention}

Although blushing undoubtedly serves the remedial function just described, the remedial explanation offers only a partial explanation of blushing. Specifically, the remedial approach cannot easily explain instances in which people blush even though they have not behaved in an incompetent, immoral, inappropriate, or otherwise undesirable manner. For example, people sometimes blush when they are praised or honored, when others serenade them with "Happy Birthday", or when others simply stare at them (Leary and Meadows, 1991).

In a review of the psychological literature on blushing, Leary et al. (1992) proposed that the necessary and sufficient cause of social blushing is undesired social attention. Put simply, people blush when they receive attention from others that they do not desire and cannot escape. Often, people receive undesired social attention after they have behaved improperly, thereby accounting for the link between embarrassing events and blushing. However, any undesired attention - even that directed at one's positive attributes or behavior-will result in blushing, thereby accounting for the effects of both positive attention and staring. 
Leary et al. (1992) suggested that blushing shares both behavioral and functional similarities with the appeasement displays of non-human primates. Both human blushing and non-human appeasement tend to be accompanied by averted gaze and a silly, nervous smile, both are elicited by staring, and both seem to divert the attention of onlookers and reduce social threats.

At present, it is not possible to unequivocally choose among these four explanations of blushing on the basis of empirical data alone, although the undesired attention perspective appears to have fewer logical difficulties accounting for the properties of blushing than the other three theories. Furthermore, the social attention theory provides a point of departure for understanding the central mechanisms that mediate blushing.

\section{THE BRAIN AS INTERFACE}

To review, social blushing involves an involuntary and possibly innate mechanism that responds to undesired attention from other people, particularly scrutiny that connotes unfavorable evaluations or carries the potential for social rejection. It is accompanied by a pattern of autonomic arousal that bears some resemblance to an anxiety state, and blushers often, but not always, report emotional reactions involving feelings of self-consciousness or anxiety. Blushing is sensitive to the interpretation of social cues; for example, blushing correlates with audience size (Shearn et al., 1992) and with a sense of culpability for embarrassing situations (Crozier and Russell, 1992). Thus, it involves the highest levels of cognitive processes (those that involve the capacity for self-thought), an awareness of others' perceptions of oneself, and the ability to anticipate unfavorable outcomes in social encounters (Leary and Meadows, 1991). In addition, blushing can be attenuated by cognitive processes that focus one's effort on trying to blush (Boeringa, 1983; Timms, 1980). Thus, this ubiquitous response can be modulated by expectation and by the processing of environmental sensory stimuli of various modalities.

Clearly, then, the central mechanisms that mediate blushing involve not only involuntary autonomic effector systems, but higher areas that involve self-regulative thought. A schema providing for basic and higher order processing of sensory input, affective coloration of experiences, and profound influence of paralimbic areas on autonomic function has been extensively discussed by Mesulam (1985). Neurocognitive templates regarding the essential stimulus properties of encounters that involve undesired social attention might be available for comparison to sensory input during social interactions. Such templates may be innate or be based on previous experience.

One possible mechanism that may accomplish this process is the gated septohippocampal comparator system described by Gray (1987). This system is postulated to compare sensory events with internal representations of expectation.

However, blushing undoubtedly also involves the prefrontal cortex, which has access to sensory information (that has been processed in the association cortices), and which is the only neocortical area with direct connections to the hypothalamus. Prefrontal cortex is also thought to be the area of cortical representation of information processed in the limbic system. Reciprocal prefrontal projections affect both input and output of limbic neural circuits, allowing the prefrontal cortex to perform an informed gating function. In addition, prefrontal cortex has access to processed or formatted information by way of basal ganglia circuits that receive neocortical projections, again allowing comparison of information that is both more and less processed (Weinberger, 1993). Thus, mechanisms are provided for cognition to influence emotional processes.

\section{UNANSWERED QUESTIONS}

At this point, most of our knowledge of blushing is based on informed speculation, and much research is needed to address several of the mysteries of this phenomenon. For example, it appears that the experience of undesired social attention is typically accompanied by autonomic arousal, but why? What developmental processes must occur, neurologically and psychologically, before the onset of social blushing and other self-conscious emotions around age 5 (Buss et al., 1979; Lewis et al., 1989)? Why does the tendency to blush decrease in adulthood? Does it outlive its usefulness in middle age because some atavistic appeasement mechanism is no longer needed after the childbearing years, or is the decreased prevalence of blushing due to attrition of beta-adrenergic receptors in facial vein, or due to thicker, wrinkled faces? Do sociopaths, who have a lesser concern for others' evaluations, blush less often; if so, what differentiates them neurologically from normals? Similarly, do leukotomized patients and others with damaged prefrontal areas lose the ability to blush? What kinds of neurological, pharmacological, and psychological interventions are most effective in reducing chronic blushing? Clearly, the topic of blushing is ripe for both basic and clinical investigation in the neurosciences.

\section{REFERENCES}

Benedek JA (1925) Notes from an analysis of a case of erythrophobia. International Journal of Psychoanalysis, 6, 430-439.

Boeringa JA (1983) Blushing: A modified behavioral intervention using paradoxical intention. Psychotherapy: Theory, Research, and Practice, 20, 441-444.

Burgess T (1839) The Physiology or Mechanism of Blushing. J. Churchill, London.

Buss AH (1980) Self-Consciousness and Social Anxiety. W.H. Freeman, San Francisco. 
Buss AH, Iscoe I and Buss EH (1979) The development of embarrassment. Journal of Psychology, 103, 227-230.

Castelfranchi C and Poggi I (1990) Blushing as a discourse: was Darwin wrong? In: Shyness and Embarrassment: Perspectives from Social Psychology (Ed. WR Crozier), pp. 230-254. Cambridge University Press, New York.

Celesia GC, Archer CR and Chung HD (1981) Hyperphagia and obesity: Relationship to medial hypothalamic lesions. Journal of the American Medical Association, 246, 151-153.

Collier JG and Fuller RW (1983) Evidence for an effect of sodium cromoglycate on sensory nerves in man. Journal of Clinical Pharmacology, 16, 639-643.

Crozier WR and Russell D (1992) Blushing, embarrassability, and self-consciousness. British Journal of Social Psychology, 30, $177-178$

Darwin C (1872/1955) The Expression of the Emotions in Man and Animals. The Philosophical Library, New York.

Eckman P, Levenson RW and Friesen WV (1983) Autonomic nervous system activity distinguishes among emotions. Science, 221, 1208-1210.

Feldman S (1962) Blushing, fear of blushing, and shame. Journal of the American Psychoanalytic Association, 10, 268-305.

Fenichel O (1945) Psychoanalytic Theory of Neurosis. W.W. Norton, New York.

Freeman R, Waldorf HA and Dover J (1992) Autonomic neurodermatology (Part II): Disorders of sweating and flushing. Seminars in Neurology, 12, 394-407.

Ginsburg J and O'Reilly B (1987) Are blushes the same as flushes? Clinical Science, 72, Suppl. 16, 65P, Abstract no. 184.

Gray JA (1987) The Psychology of Fear and Stress, 2nd edn. Cambridge University Press, Cambridge.

Hamilton L (1989) Fight, flight, or freeze: Implications of the passive fear response for anxiety and depression. Phobia Practice and Research Journal, 2, 17-27.

Harris PR (1990) Shyness and embarrassment in psychological theory and ordinary language. In: Shyness and Embarrassment: Perspectives from Social Psychology (Ed. W.R. Crozier), pp. 59-86. Cambridge University Press, Cambridge.

Hubert W and de Jong-Meyer R (1990) Psychophysiological response patterns to positive and negative film stimuli. Biological Psychology, 31, 73-93.

Karch FE (1971) Blushing. Psychoanalytic Review, 58, 37-50.

Krause U, Nink M, Brauer A, Huber I, Velten A, Lehnert $\mathrm{H}$ and Beyer J (1991) Studies on facial temperature rise and involvement of serotonin in the respiratory stimulation by CRH. Hormonal and Metabolic Research, 23, 499-503.

Leary MR (1983) Understanding Social Anxiety: Social, Personality, and Clinical Perspectives. Sage, Beverly Hills.

Leary MR and Meadows S (1991) Predictors, elicitors, and concomitants of social blushing. Journal of Personality and Social Psychology, 60, 254-262.

Leary MR, Rejeski WJ and Britt TW (1990). Distinguishing embarrassment from social anxiety. Paper presented at the meeting of the American Psychological Society, Dallas, June.

Leary MR, Britt TW, Cutlip WD and Templeton J (1992) Social blushing. Psychological Bulletin, 112, 446-460.

Lewis M, Sullivan MW, Stanger C and Weiss M (1989) Selfdevelopment and self-conscious emotions. Child Development, 60, 146-156.

MacCurdy JT (1930) The biological significance of blushing and shame. British Journal of Psychology, 21, 174-182.
Mellander S, Andersson P, Afzelius L and Hellstrand P (1982) Neural beta-adrenergic dilatation of the facial vein in man: Possible mechanism in emotional blushing. Acta Physiologica Scandinavia, 114, 393-399.

Mesulam MM (1985) Patterns in behavioral neuroanatomy: Association areas, the limbic system, and hemispheric specialization. In: Principles of Behavioral Neurology (Ed. MM Mesulam), pp. 1-70. F.A. Davis, Philadelphia.

Miller RS and Leary MR (1992) Social sources and interactive functions of emotion. The case of embarrassment. Emotion and Social Behavior (Ed. MS Clark). Sage, Newbury Park, CA

Phillips WS and Lightman SL (1981) Is cutaneous flushing prostaglandin mediated? Lancet, April 4, 754-756.

Ryan TJ (1973a) Measurement of blood flow and other properties of the vessels of the skin. In: The Physiology and Pathophysiology of the Skin, Vol. 2, The Nerves and Blood Vessels (Ed. A Jarrett). Academic Press, New York.

Ryan TJ (1973b) Structure, pattern and shape of the blood vessels of the skin. In: The Physiology and Pathophysiology of the Skin, Vol. 2, The Nerves and Blood Vessels (Ed. A Jarrett). Academic Press, New York.

Rybakowski J and Weterle R (1991) Niacon test in schizophrenia and affective illness. Biological Psychiatry, 29, 834-836.

Semin GR and Manstead ASR (1982) The social implications of embarrassment displays and restitution behavior. European Journal of Social Psychology, 12, 367-377.

Shearn D, Bergman E, Hill K, Abel A and Hinds L (1990) Facial coloration and temperature responses in blushing. Psychophysiology, 27, 687-693.

Shearn D, Bergman E, Hill K, Abel A and Hinds L (1992) Blushing as a function of audience size. Psychophysiology, 29, 431-436.

Shields SA, Mallory ME and Simon A (1990) The experience and symptoms of blushing as a function of age and reported frequency of blushing. Journal of Nonverbal Behavior, 14, 171-187.

Smith EN and Tobey EW (1983) Heart rate response to forced and voluntary diving in swamp rabbits. Physiological Zoology, 56, 632-638.

Smith EN, Allison RD and Crowder WE (1974) Bradycardia in a free ranging American alligator. Capeia, 3, 770-772.

Templeton J and Leary MR (1991) Staring as a blush-inducing stimulus: Evaluation apprehension or visual threat? Paper presented at the meeting of the Southeastern Psychological Association, New Orleans.

Timms MWH (1980) Treatment of chronic blushing through paradoxical intention. Behavioral Psychotherapy, 8, 59-61.

Waldenstrom JG (1977) From maiden blush to matron's flush. Acta Medica Scandinavia, 201, 1-2.

Weinberger DR (1993) A connectivist approach to the prefrontal cortex. Journal of Neuropsychiatry, 201, 241-253.

Wilkin JK (1983) Flushing reactions. In: Recent Advances in Dermatology, Vol. 6 (Eds AJ Rook and HI Maibach). Churchill-Livingston, New York.

Wilkin JK (1988) Why is flushing limited to a mostly facial cutaneous distribution? Journal of the American Academy of Dermatology, 19, 309-313.

(Received 21 September 1993; accepted 16 October 1993) 


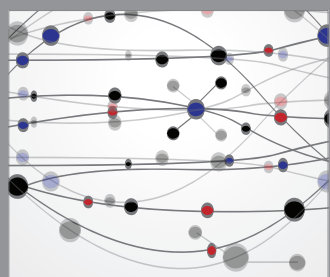

The Scientific World Journal
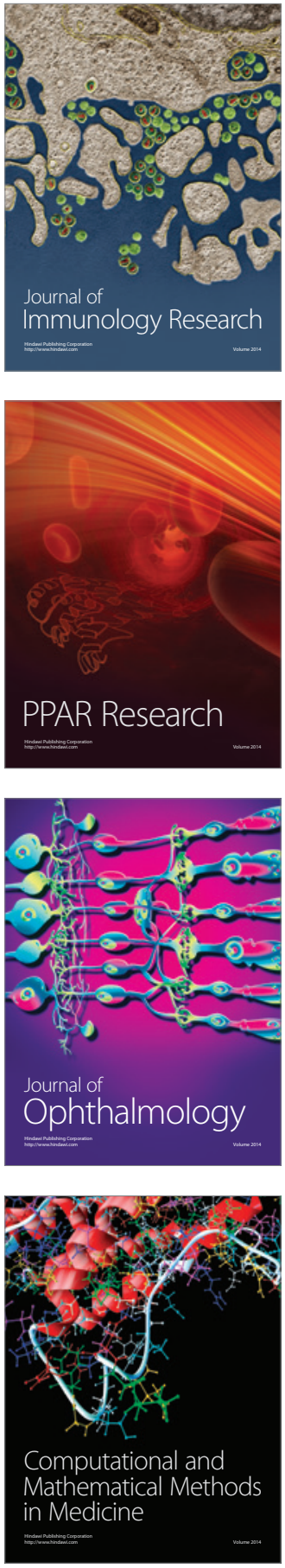

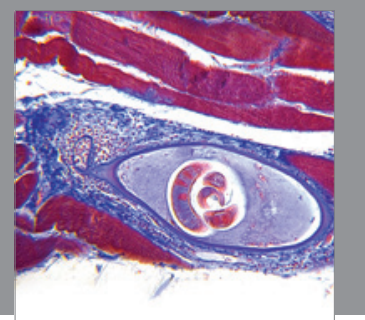

Gastroenterology

Research and Practice
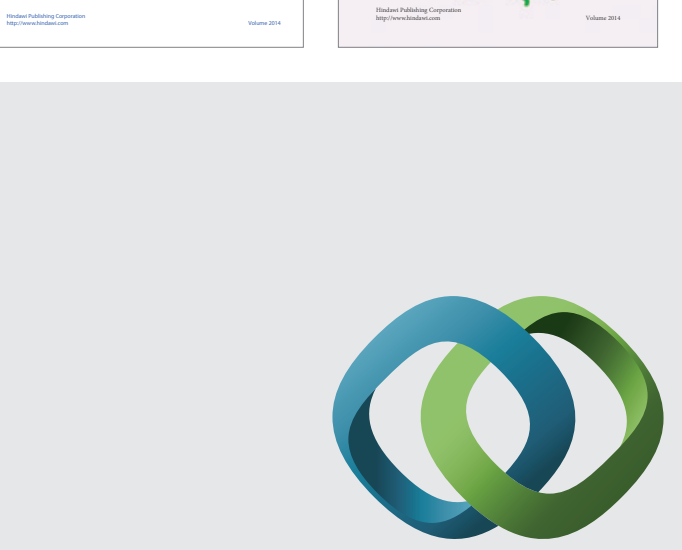

\section{Hindawi}

Submit your manuscripts at

http://www.hindawi.com
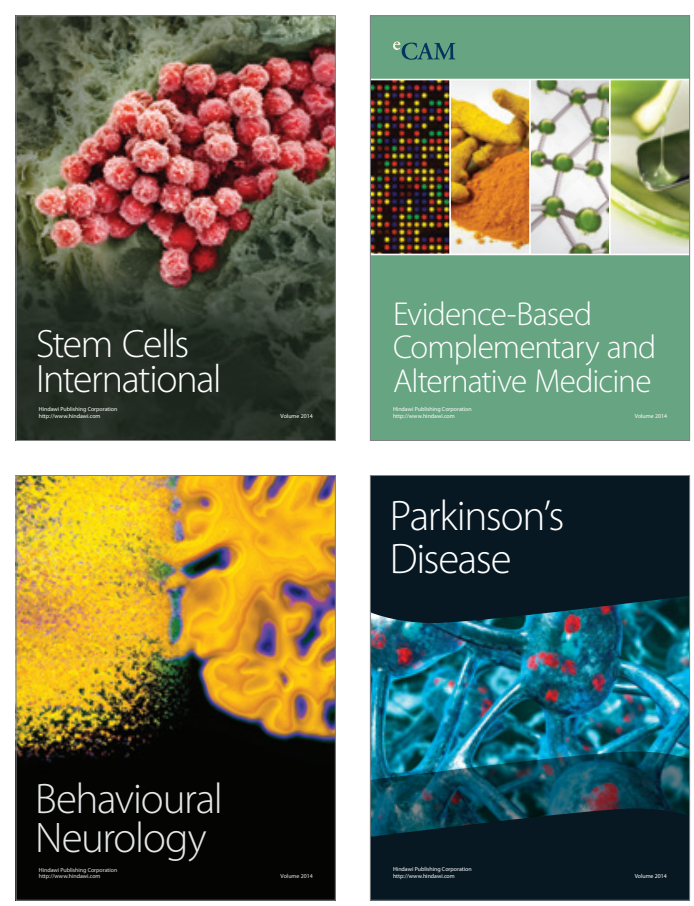

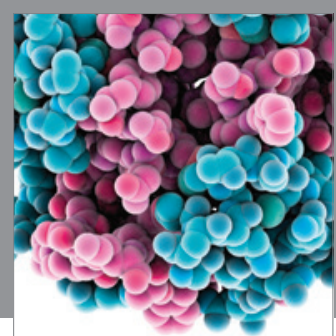

Journal of
Diabetes Research

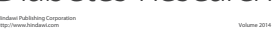

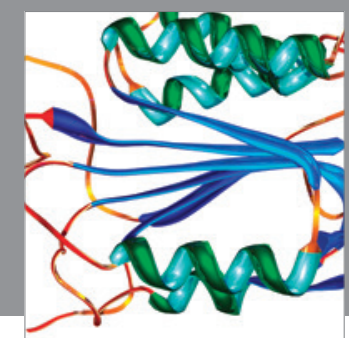

Disease Markers
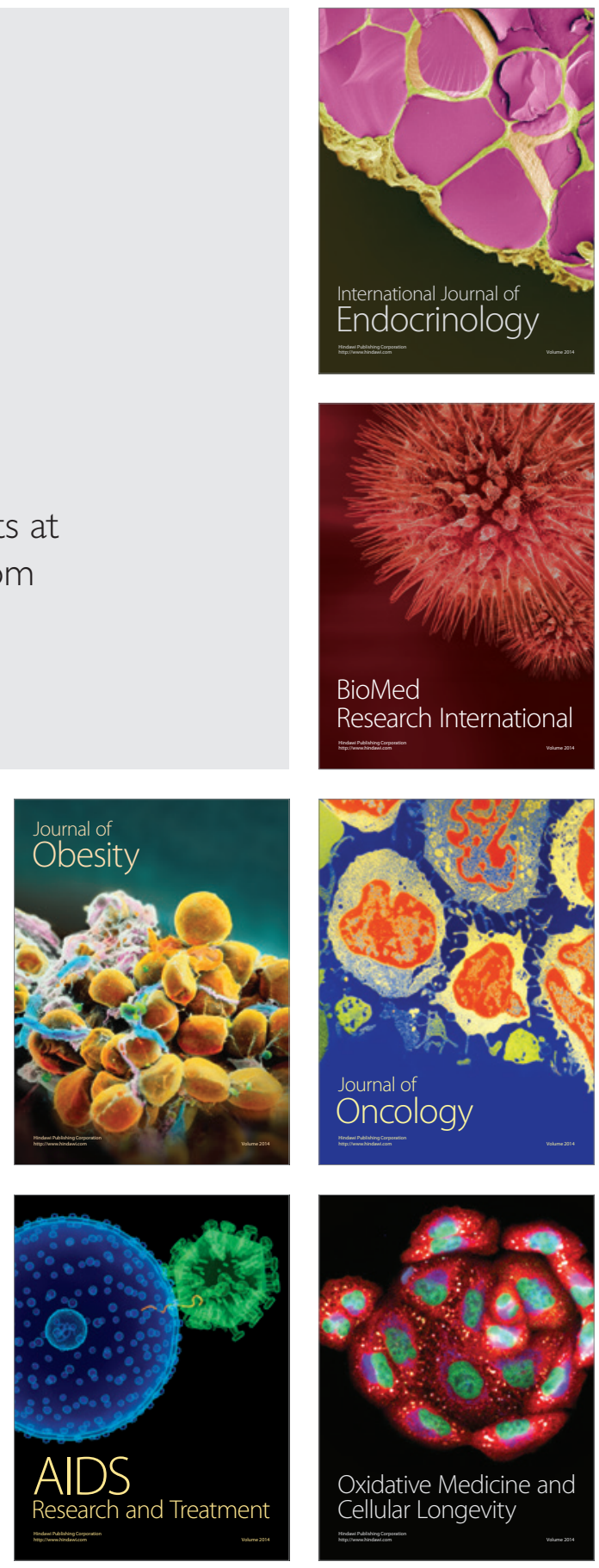